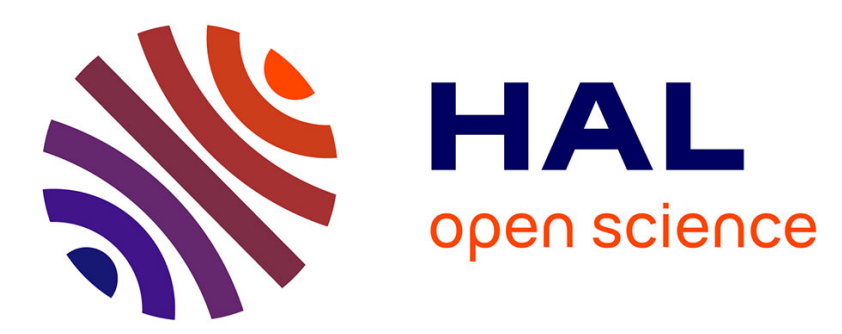

\title{
Toward generalization of futures contracts for raw materials: A probabilistic answer applied to metal markets
}

Florian Fizaine

\section{- To cite this version:}

Florian Fizaine. Toward generalization of futures contracts for raw materials: A probabilistic answer applied to metal markets. Resources Policy, 2018, 59, pp.379-388. halshs-01957410

\section{HAL Id: halshs-01957410 \\ https://shs.hal.science/halshs-01957410}

Submitted on 17 Dec 2018

HAL is a multi-disciplinary open access archive for the deposit and dissemination of scientific research documents, whether they are published or not. The documents may come from teaching and research institutions in France or abroad, or from public or private research centers.
L'archive ouverte pluridisciplinaire HAL, est destinée au dépôt et à la diffusion de documents scientifiques de niveau recherche, publiés ou non, émanant des établissements d'enseignement et de recherche français ou étrangers, des laboratoires publics ou privés. 
Toward generalization of futures contracts for raw materials: A probabilistic answer applied to metal markets

\section{Fizaine Florian $^{\mathrm{a}}$}

a Univ. Savoie Mont-Blanc, IREGE, 4 Chemin de Bellevue, 74944 Annecy-le-Vieux, France. Email: florian.fizaine@gmail.com

\section{Abstract}

In this paper, we aim at identifying root causes linked to presence or absence of futures contracts for raw materials. Unlike previous analyses focused on the success of futures contracts via exchange volume and open interest, we offer an alternative logit model applied to the presence or absence of futures contracts for 53 metal markets. We use different factors (price and physical quantities produced, geographical concentration...) and several combinations of variables in order to explore the root causes of futures contracts. The model shows both great explaining capability and a good prediction power which are robust to data resampling. According to the model, it is unlikely that minor metals successfully introduce futures contracts in the coming years. We also discuss the use and interest of this model by institutions and financial authorities devoted to the development of futures contracts for raw material markets.

Key words: Financialization - Futures contract - Raw materials - Logit model - Metals

JEL classification : C25 ; C52 ; G13 ; Q130 


\section{Introduction}

After an exceptional price surge during the first decade of the twenty-first century, prices of both metals and energy have fallen, indicating an era of greater volatility in these markets (Daviron, 2012; FAO et al., 2011; HLPE, 2011). Raw material financialization has been repeatedly identified as a source of raw-material price destabilization, because of its promotion of market speculation (especially through non-commercial trading). However, this "conventional wisdom" remains highly controversial (Haase et al., 2016; Hache and Lantz, 2014; World Bank, 2011); recent studies tend either to identify follower behavior as the cause of speculation (Arik and Mutlu, 2014) or to find no significant impact (Miffre and Brooks, 2013). Some scholars show that increasing price volatility attracts speculative trading, but not the reverse; according to Mayer et al. (2017), there is no significant impact of general trading activity on raw-material price levels. As Bicchetti and Maystre (2013) assert, "financialization of raw material commodities is seen as the phenomena of growing importance of financial and institutional investors in commodity trading for merely financial motivations ${ }^{1}$." This financialization is made possible by non-commercial traders' and investors' identification of raw material commodities as common portfolio assets (Mongars and Marchal-Dombrat, 2006).

Accordingly, the increasing volume of futures contracts appears to reflect the strengthening of the role of financial investors in raw material markets. However, we also must exclude the development of over-the-counter (OTC) instruments such as forward contracts from financialization phenomena, because the extreme customization relative to these contracts is designed to ensure physical delivery of the underlying asset to various stakeholders (Carlton, 1984), and they thus do not attract investors and speculators. Scholars have offered many explanations for the increasing price volatility of raw material markets, mostly related to the instability of supply and/or demand of commodity markets. These explanations include the accelerated development (due to dietary changes and urbanization), the global economic crisis, energy transitions, decreasing productivity of agricultural resources resulting from supply-side shocks, growing interdependency between natural resources and energy, adoption of justin-time delivery practices by processors (decreasing storage buffers), and the generalization of coproduction (or by-production) through the rationalization of the production process (Bicchetti and Maystre, 2013; Fizaine, 2013; Humphrey, 2010; Redlinger and Eggert, 2016).

Whatever the roles - none, minor, or major-played by non-commercial traders in the surge of rawmaterial price volatility, such volatility is likely to increase commercial traders' (i.e., producers' and consumers') need to hedge. In these circumstances, we can ask whether this general context will lead to the intensive introduction and use of futures contracts for raw materials. Although one of the main goals of futures contracts - in addition to price discovery, information transmission, and the creation

\footnotetext{
${ }^{1}$ Author translation.
} 
of private storage (Goss, 1986) — is the promotion of risk management (hedging), price uncertainty and/or high price volatility should not be enough to trigger the creation of futures contracts. For instance, there are no futures contracts for minor metals ${ }^{2}$ (distinct from precious or major metals [Fizaine, 2015a]), even though minor metals exhibit higher price volatility (Fizaine, 2015b). Moreover, several authors argue that the introduction of futures contracts is correlated with decreases in price volatility and increases in integration with other commodity markets (Jacks, 2007; Arik and Mutlu, 2014; Fizaine, 2015b).

In view of the circumstances and important consequences related to the introduction of futures contracts, we explore the determinants of futures contracts. Why do some raw material commodities have futures contracts while others do not? To answer this question, we structure this paper as follows: Section 2 offers a literature review of factors that promote or discourage the use of futures contracts. Section 3 presents the data and methodology. Section 4 provides main outcomes attached to the use of a logit model applied to 53 metal markets to explain the presence or absence of futures contracts. Section 5 discusses both the limitations of the model and the value of the model for financial institutions, and it contextualizes the results in light of prior literature and history. Section 6 concludes.

\section{Literature review: Causes of futures contracts emergence}

If uncertainty were the sole creator of futures contracts, there would be futures contracts for almost all minor metals. Therefore, it is more likely that, to create and keep futures contracts, commodity markets must fulfill a range of prerequisites. One can suppose that whereas major metal markets have met these parameters, minor metal markets have not. Anyway, the identification of necessary conditions to create successful futures contract has long been a source of concern for scholars (e.g., Houthakker, 1959). Accordingly, using Black's (1986) typology, we explore the prerequisites of futures contracts by examining two perspectives: (1) characteristics related to commodities and (2) characteristics related to futures contracts.

\subsection{Specific characteristics of commodities}

Leuthold et al. (1989) suggest five main characteristics of underlying assets (specific commodities) that are likely to promote both the creation and success of futures contracts. Other authors identify additional characteristics. All of these criteria have been resumed in the following list:

\footnotetext{
${ }^{2}$ Although there is no consensus on the definition of minor metals, Fizaine (2015) and Redlinger and Eggert (2016) provide several criteria, including low volume of production ( $<200 \mathrm{kt}$, i.e 200 thousand tons), high geographical concentration of the production, high supply, demand, and price volatility, remaining in relative opacity because of very restricted public data, limited recycling, and typically not traded on exchange.
} 
- The product is homogenous. For some authors (Hedge, 2004; Kohls, 1955), this prerequisite is crucial, whereas others do not consider it necessary or sufficient when it co-exists with high, steady price correlations between different qualities and localizations of a product (Carlton, 1984; Gray, 1966; Powers, 1967; Thompson et al., 1996). A low spatial-price correlation instead makes inefficient use of futures contracts for hedging purposes for agents who are located outside delivery areas.

- The commodity is associated with a high level of production standardization and a low degree of differentiation.

- Cash market prices fluctuate and/or are uncertain (Maliaris 2000; Sanders and Manfredo, 2002; Telser, 1981).

- There is adequate size, activity level, and numbers of agents (with low market power) in cash markets (Carlton, 1984; Gray, 1966; Hedge, 2004). Carlton (1984) adds that vertical integration discourages the introduction of futures contracts because of the efficiency of the market structure to suppress price risk for necessary inputs.

- Information about production and stock is publicly available. Conversely, the possibility of cross-hedging may discourage the creation of futures contracts for specific commodities [Black 1986].

- The supply of raw material fluctuates (due to seasonal or weather conditions), which promotes speculative elements (Gray, 1966). The opposite prevails when demand is subject to uncertainty. Gray (1961) acknowledges that the argument is based more on opacity (limited information) and less on predictability of metal demand.

- The commodity is storable (Goss, 1986). Gray (1966) and Powers (1967) argue that storability does not prevent the success of futures contracts if the perishability of commodity does not preclude delivery at any time.

- There is no government regulation of the commodity (Carlton, 1984; Gray 1966) (e.g., U.S. prohibition of futures contracts for onions since 1958) or the constitution of alternative public stockpiles (e.g., butter, cotton) ${ }^{3}$.

Minor metals do not meet most of these criteria. Minor metal markets are micro-markets with values ranging from several million to several billion dollars per year ${ }^{4}$ (see figure 1); given the limited application of each metal, their markets have few producers and consumers (Sykes et al., 2016). Furthermore, production of many of these metals is highly concentrated, often in China, a country that

\footnotetext{
${ }^{3}$ These alternatives public stockpiles can reduce the incentive to keep stockpiles for private actors or they can arbitrary influence the market in case of unwise management.

${ }^{4}$ These figures correspond to the economic value of the production associated with these metals.
} 
is deliberately interventionist and partisan with regard to regulation (e.g., exportation quotas, taxes on rare-earth elements).

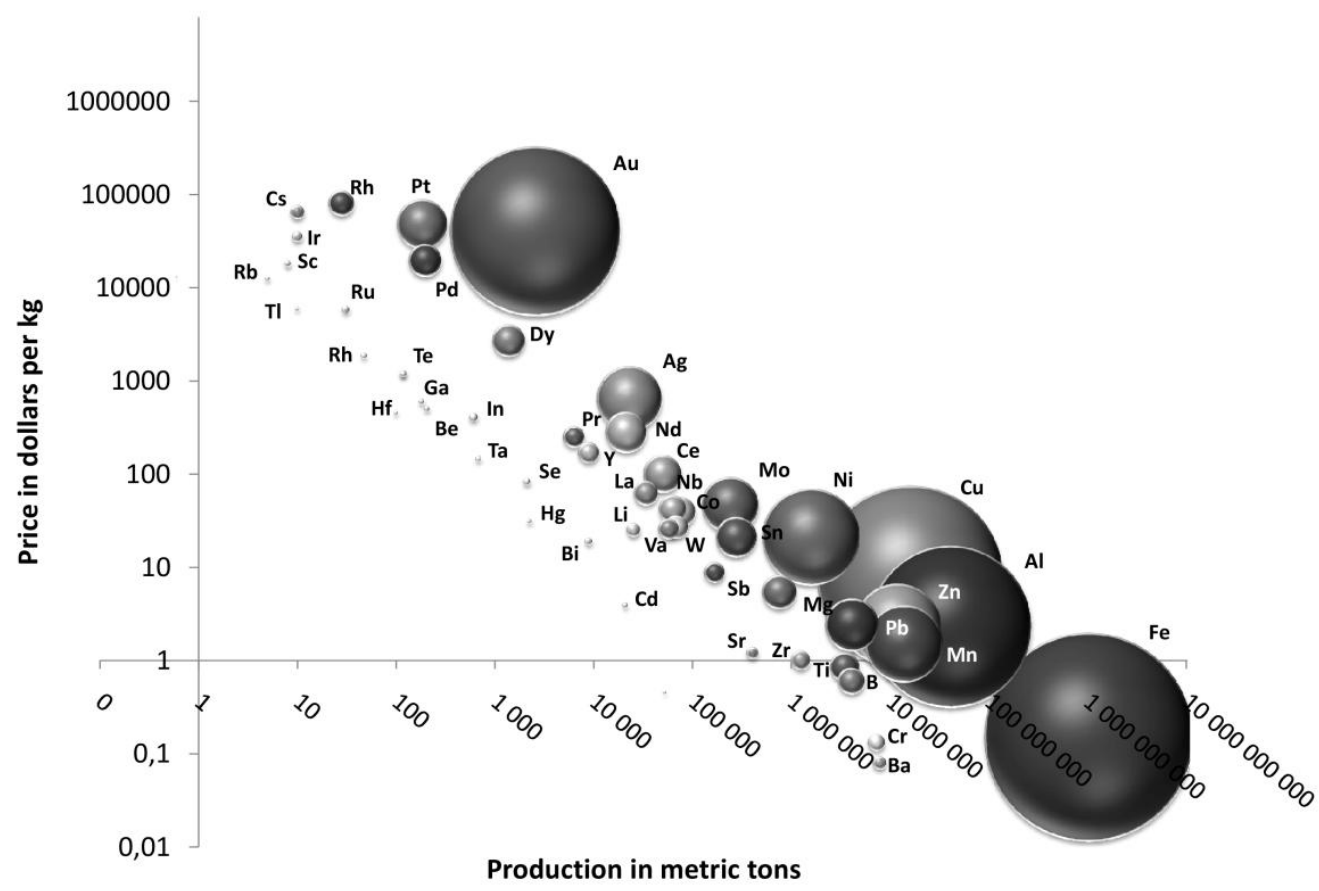

Figure 1 Market size of different metal markets analyzed in the study. Source: author's calculations

\subsection{Specific characteristics of futures contracts}

The characteristics of futures contracts also affect their success or failure (Leuthold et al., 1989; Pirrong et al., 1991). According to Goss (1986), futures contracts feasibility is determined more by these characteristics than by the general economic factors of commodities.

A necessary condition of futures contracts success is an ability to attract speculators, which is an absolute precondition of market liquidity (Gray, 1961; Working, 1962). Futures contracts that have few speculators are unbalanced (in favor of sellers; Gray, 1961), because of the non- symmetrical hedging needs of hedgers (commercial traders). In these circumstances, lack of liquidity anticipates the eventual death of the futures contract; it causes huge price fluctuations as contract orders are bought and sold (Gray, 1977) and results in rapid leakage of remaining commercial traders. ${ }^{5}$ Powers (1967) asserts that speculators are attracted by futures contracts that involve huge volumes of hedging and repelled by futures contracts that have few or no commercial agents (hedgers). Therefore, we can

\footnotetext{
${ }^{5}$ Markets with poor liquidity - also called narrow markets - show large spreads, high transaction costs and low market depth, all making them unattractive to speculators and hedgers alike.
} 
reframe the issue as follows: Which conditions of futures contracts ensure their attractiveness to hedgers?

Hedge (2004) maintains that the success of futures contracts is associated mainly with their ability to provide an efficient hedge for all hedgers, that is, a supply of the closest substitute for the physical commodity (Gray, 1960). To avoid failure, futures contracts thus must include accurate descriptions of both commodity characteristics and conditions of delivery (location, delivery times). Success also depends on agents' predispositions to boycott or promote futures contracts; the latter choice arises from other factors, such as needs, habits, or market powers. As suggested by Sanders and Manfredo (2002), existing trading practices partly determine an industry's interest in and need for commodity futures contracts; they are the reason that futures contracts that are unbalanced, badly adjusted, or simply unwanted tend to fail. For example, in an analysis of the pork market, Powers (1967) shows that six clauses inherent to futures contracts made the financial market unsuitable for hedgers, which restricted its growth (i.e., exchange volume and open interest) during its two first years of operation. Fortunately, in 1963, when the Chicago Mercantile Exchange acted on complaints from futures contracts users, revised these clauses, and fixed their deficiencies, the market became successful. This lesson led Sanders and Manfredo (2002) to recommend that the opinions of customers should dominate setting futures contracts and that industrial actors should be involved in the process to ensure their support. It is also important to consider education and information related to risk management if an industry lacks financial knowledge associated with these tools. Ignorance of the mechanisms of financial markets often leads commercial agents (i.e., producers) to exhibit hostility toward financial tools, thereby preventing the rise of futures contracts (Jacks, 2007).

Finally, the decrease of risks associated with futures contracts compared with other markets are key determinants of futures contract success. Risks without futures contract include the difficulty of finding counterparties in OTC markets (liquidity risk) and the risk associated with counterparties. From that perspective, the success of futures contracts depends on their ability to provide attractive futures contracts suitable for the large part of actors in order to limit these risks successfully or at least manage them better.

\subsection{Past analytical and quantitative studies of factors in futures contracts' success/failure}

A few studies that focus on causes of the success or failure of futures contracts can be classified into two groups. One group uses analytical tools to identify main variables, and the other uses quantitative (i.e., statistical) tools.

Telser and Higinbotham (1977) suggest that futures contracts allow both risk hedging and liquidity. These tools limit counterparty risks through clearing houses and margin calls. However, introducing and maintaining a clearing house is costly (clearing fee) and is often useless when markets involve few 
economic agents or changes. These authors propose a wide range of criteria that affect the costs and benefits associated with futures contracts. The costs of futures contracts depend positively on exchanged volumes, open interest, and price standard deviations, and the benefits depend positively on exchanged volumes, open interest, expected price variations, and number of economic agents using the futures contracts. With regard to the form of the model, Goss (1986) points out that though the existence of futures contracts is predetermined according to Telser and Higinbotham (1977), it is endogenous to the contractual form, because of transaction costs and property rights, as identified by Veljanovoski (1986). According to Veljanovoksi, futures contracts are more efficient for these criteria than other types of markets (cash, forward contracts) because of scale economies that lead to faster growth and market domination. Accordingly, Telsen and Higinbotham's work (1977) seems to support the idea that benefits associated with the introduction of futures contracts for minor metals are greatly reduced because of their relatively few producers (Brooks, 1965).

Thompson et al. (1996) use a telephone survey of suppliers and customers of fructose syrup to show that market actors constitute can identify the main variables of futures contracts failure. In the survey, suppliers identify the main causes of failure as market concentration in the industry, poor specification of contracts (i.e., commodity quality, delivery conditions), lack of correlation between futures prices and cash prices, lack of liquidity, and lack of price volatility. Customers identify the same weaknesses as suppliers, with the exception of liquidity. In this case, lack of liquidity quickly causes commercial users to flee, leaving the market to mainly non-commercial, uninformed traders. A few commercial traders (producers) might participate in the futures contract, but only for speculative reasons - that is, to benefit from higher prices relative to cash markets.

In an economic study, Brorsen and Fofana (2001) use cross-sectional data from agricultural research and an econometric model to identify the effects of several variables on the success of futures contracts, according to the proxy variables of exchanged volume and open interest. They find that three variables - price volatility, market size, and commodity homogeneity—have positive impacts on the proxies of futures contracts success; conversely, liquidity costs and the market concentration of consumers have negative impacts. However, their study suffers three limitations. First, several variables (e.g., homogeneity) are not directly quantifiable. The authors overcome this difficulty by using the Delphi method ${ }^{6}$ (N'Zue, 1995), so their finding of a positive and unexpected effect of vertical integration on the success of futures contracts might be explained by the effects of using this approach. Second, the authors focus on commodity markets that include futures contracts, reflecting the form of their model and the greater availability of public data about these markets. Although this approach is logical, it limits explanation of the absence of futures contracts. Third, with mixed

\footnotetext{
${ }^{6}$ The Delphi method aims to organize communication between several experts on a specific issue. Usually, this method uses several successive surveys, with treatment of the answers within the group.
} 
findings, Hedge (2004) analyzes three unsuccessful futures contract introductions of cattle and broiler markets. In a reiteration of the argument put forward by Brown (2001), Hedge uses monthly volumes of futures contracts as a proxy for futures contracts success, according to (1) price volatility in the cash markets (positive signs for cattle and broilers), (2) reduction or excess of risks as the result of crosshedging practices (not significant), (3) monthly volume of futures contracts in cross-hedging markets (positive and significant for cattle and broiler, in contradiction of theory), (4) cash market size (positive and significant for cattle), and (5) basis risk (i.e., the imperfect correlation between cash price and futures prices; it was negative and significant for cattle and broiler). The study mixed results include insignificant findings for some variables used in the model to explain the failure of broiler futures contracts.

We therefore conduct a new quantitative analysis of the main determinants of futures contracts success and seek to make three main contributions. First, we explore the presence or absence of futures contracts using dichotomous codification rather than a quantitative variable (e.g., volume exchanged). Second, this study estimates the probability of establishing a futures contract for a commodity that currently lacks such a market but is subject to its introduction (a step that was not possible in past studies that thus explain success ex post). Third, this study is the first one that focuses on metal markets, specifically minor metal markets.

\section{Methodology and data}

\subsection{Data}

Our data are drawn from the database provided by the USGS (2015), or private institutions (MetalPages, various mining company reports) if the database was lacking. We collected price and annual production figures for 53 metals markets and (where possible) computed volatility over the last 20 years, as the standard deviation of the annual price yield (or annual production) over that period. All data are from 2010 (cross-sectional), the year for which we have the maximum number of observations $(\mathrm{n}=53)^{7}$

\subsection{Model selection}

Our assumption with regard to metals is that the creation (thus presence) of futures contracts mostly depends on market size. The larger the market, the higher the costs associated with the absence or limitation of available information. A large market might result from either a high price-per-quantity or high quantities produced. Yet the larger the market, the lower the transaction costs relative to the market's size and the lower the value of an exchange. Beyond a specific threshold, the introduction of futures contracts should be profitable, because the economic benefits of this form of organization

\footnotetext{
${ }^{7}$ Some values of minor metals for more recent years are unavailable.
} 
exceed the economic costs of their introduction. There are many factors related to the costs and benefits of futures contract; we adopt market size as a good proxy for other factors.

In these conditions, we can use a logit econometric model to explain the absence or existence of futures contracts for the 53 metal markets. We explain the probability of existence of futures contracts by the market size of the metal. We also test other variables, such as price per kilogram, quantities produced, price volatility, production volatility (of the cash market), geographical concentration, and by-product nature of the production (Redlinger and Eggert, 2016). The logit model regresses the probability to have futures contract on these variables (in logarithm form or not ${ }^{8}$ ). The probability $\mathrm{p}_{\mathrm{i}}$ that the metal i has a futures contract is described by the following relationship:

$$
\begin{gathered}
P_{i}=\operatorname{Prob}\left(F C_{i}=1\right)=\operatorname{Prob}\left[\alpha+\beta_{1} \ln \left(\operatorname{Size}_{i}\right)+\mu_{i}\right] \\
\text { With } i=1, \ldots, n,
\end{gathered}
$$

where $F C$ is a dummy variable coded as 1 when the metal has a futures contract and 0 otherwise, and Size is the market size of the cash market in dollars. We can also express the probability of the logit model in Equation (1) with a simple form:

$$
\ln \left(\frac{p_{i}}{1-p_{i}}\right)=\alpha+\beta_{1} \ln \left(\text { Size }_{i}\right)+\mu_{i}
$$

We consider other specifications of the model too:

$$
\begin{gathered}
\ln \left(\frac{p_{i}}{1-p_{i}}\right)=\alpha+\beta_{1} \ln \left(\text { Production }_{i}\right)+\beta_{2} \ln \left(\text { Price }_{i}\right) \mu_{i} ; \\
\ln \left(\frac{p_{i}}{1-p_{i}}\right)=\alpha+\beta_{1} \ln \left(\text { Size }_{i}\right)+\beta_{2}\left(\text { Volprod }_{i}\right)+\mu_{i} ; \\
\ln \left(\frac{p_{i}}{1-p_{i}}\right)=\alpha+\beta_{1} \ln \left(\text { Size }_{i}\right)+\beta_{2}\left(\text { Concentration }_{i}\right)+\mu_{i} ; \\
\ln \left(\frac{p_{i}}{1-p_{i}}\right)=\alpha+\beta_{1} \ln \left(\text { Size }_{i}\right)+\beta_{2}\left(\text { Volprod }_{i}\right)+\beta_{3} \ln \left(\text { Volprice }_{i}\right)+\mu_{i} ;
\end{gathered}
$$

where Production represents the physical production of metal i, Price represents the value of metal i in dollars per kg, Volprod and Volprice represent the historical volatility of the production and the price of metal i, and Concentration is a Herfindahl-Hirschman index computed on the first five more important producing countries of metal i.

We selected the various specifications of the model cautiously because of the limited number of observations $(\mathrm{n}=43-53)$. This limitation prevented us from employing all the variables simultaneously, in that such a model cannot be estimated. To enable estimations for small, nontransparent, minor metals markets, we also favored specifications for which it was easy to find data.

\footnotetext{
${ }^{8}$ Some variables are linearized because it reduces their important dispersion. In addition, information criteria (Bayesian information criterion [BIC], Akaike information criterion [AIC]) lead us to favor these specifications.
} 
Finally, we computed the variance inflation factor of each specification to detect the degree of collinearity between predictors; collinearity does not bias coefficients, but it can greatly inflate the variance of the estimators and lead to insignificant results.

\section{Results}

\subsection{Interpretation of results}

The values associated with each coefficient cannot be interpreted directly in the logit model (Table 1). However, the sign of the coefficients remains interpretable without any transformation. For example, the coefficients of the variables $\log$ (production) and $\log$ (price) (Specification B) have a positive and significant impact (at $1 \%$ of risk) on the likelihood that the metal has a futures contract. In this respect, the probability that gold has a futures contract can be computed as follows:

$$
P_{\text {gold }}=\frac{1}{1+e^{-\left[\alpha+\beta_{1} \times \ln (2560)+\beta_{2} \times \ln (40000)\right]}}=99.95 \% .
$$

The confidence interval can be estimated from the standard deviation of the regression (0.25). For example, for gold, at the 5\% risk threshold, the probability estimated by Specification B is $99.95 \%$, with a confidence interval ranging from $99.92 \%$ to $99.97 \%$. According to the model, it is likely that gold has a futures contract. Figures 2 and 3 show all predictions of Specification B.

We can also interpret our results according to the odds ratio, which we obtain from the exponential of the coefficients $\alpha$ and $\beta$. The odds ratio expresses the ratio between the probability of success (i.e., presence of futures contract) and the probability of failure (i.e., no futures contract). For example, the exponential of the intercept in Specification A shows the probability of a specific metal to have futures contract, with a cash market value equal to 0 . Unsurprisingly, in these conditions, the probability to have a futures contract is nearly $0\left(1.37 \times 10^{-8}\right)$. Moreover, the exponential of $\beta_{1}$ and $\beta_{2}$ coefficients in Specification B shows the effect on the odds ratio relative to an increase of one unit in the logarithm production (ton) or price (\$ per kilogram). In our case, at the medium point, one more unit of production in the logarithm value multiplies the odds ratio by 9.56 (12 for price). This important impact on the odds ratio hides the key variables required to change the production or price in logarithm form. At the mean, ${ }^{9}$ an increase of one unit of log production represents an increase of 20,800 tons of metal production per year ( $\$ 160 /$ kilogram for the price); the notion of elasticity becomes more relevant because it measures relative variations between two variables. The elasticity of the logit model is not the same for each variable but rather depends on the point of estimation. At the mean, the elasticity of the probability to have a futures contract relative to production is 2.35 (2.52 for

\footnotetext{
${ }^{9}$ The mean of the sample represents a production of 12,700 tons per year and a price per kilogram of $\$ 92$, which is nearly equivalent to lanthanum or cerium (two rare-earth elements).
} 
price). That is, a $1 \%$ increase in metal production increases the probability of a futures contract for a specific metal by $2.35 \%$.

\begin{tabular}{|c|c|c|c|c|c|}
\hline \multirow[t]{2}{*}{ Variable } & \multicolumn{5}{|c|}{ Dependent variable : FC (absence or presence of futures contracts) } \\
\hline & A & B & C & D & $\mathbf{E}$ \\
\hline Intercept & $\begin{array}{c}-18.10288 \\
(6.409190)^{* * *}\end{array}$ & $\begin{array}{c}-36.44660 \\
(10.62435)^{* * *}\end{array}$ & $\begin{array}{c}0.968130 \\
(3.275453)\end{array}$ & $\begin{array}{c}-14.46042 \\
(6.379944)^{* *}\end{array}$ & $\begin{array}{c}0.969651 \\
(3.304814)\end{array}$ \\
\hline $\log ($ Size $)$ & $\begin{array}{c}2.064246 \\
(0.777763)^{* * *}\end{array}$ & - & $\begin{array}{c}1.542141 \\
(0.707202)^{* *}\end{array}$ & $\begin{array}{c}1.791907 \\
(0.844099)^{* *}\end{array}$ & $\begin{array}{c}1.542975 \\
(0.691527)^{* *}\end{array}$ \\
\hline $\log ($ Price) & - & $\begin{array}{c}2.485867 \\
(0.702332)^{* * *}\end{array}$ & - & - & - \\
\hline $\log$ (Production) & - & $\begin{array}{c}2.258340 \\
(0.690931)^{* * *}\end{array}$ & - & - & - \\
\hline Volprod & - & - & $\begin{array}{c}-128.3158 \\
(35.32648)^{* * *}\end{array}$ & - & $\begin{array}{c}-128.2856 \\
(35.59103)^{* * *}\end{array}$ \\
\hline $\log ($ Volprice $)$ & - & - & - & - & $\begin{array}{c}0.013323 \\
(0.606720)\end{array}$ \\
\hline Concentration & - & - & - & $\begin{array}{c}-0.000491 \\
(0.000252)^{*}\end{array}$ & - \\
\hline $\mathrm{R}^{2}$ & 0.645213 & 0.674746 & 0.816352 & 0.656153 & 0.816353 \\
\hline Nagelkerke $\mathrm{R}^{2}$ & 0.763 & 0.787 & 0.895 & 0.782 & 0.895 \\
\hline AIC & 0.470771 & 0.475601 & 0.364622 & 0.560968 & 0.411132 \\
\hline $\mathrm{BIC}$ & 0.545122 & 0.587127 & 0.487496 & 0.683843 & 0.574964 \\
\hline $\mathrm{N}$ & 53 & 53 & 43 & 43 & 43 \\
\hline VIF max & I & 28.01 & 2.32 & 1.01 & 2.36 \\
\hline Hosmer-Lemeshow & 0.6047 & 0.4805 & 0.2522 & 3.691 & 0.2519 \\
\hline Mann-Whitney & $-5.0648 * * *$ & $-5.0854 * * *$ & $-5.0773 * * *$ & $-4.8922^{* * *}$ & $-5.0773 * * *$ \\
\hline Score de Brier & 0.062 & 0.059 & 0.039 & 0.061 & 0.039 \\
\hline Critère AUC & 0.971 & 0.973 & 0.9925 & 0.9745 & 0.9925 \\
\hline
\end{tabular}

Table 1 Main results from different logit models. Risk threshold: $* 10 \%$, **5\%, ***1\%. Robust covariance: QML (Huber/White) standard errors \& covariance. Source: author's calculations 


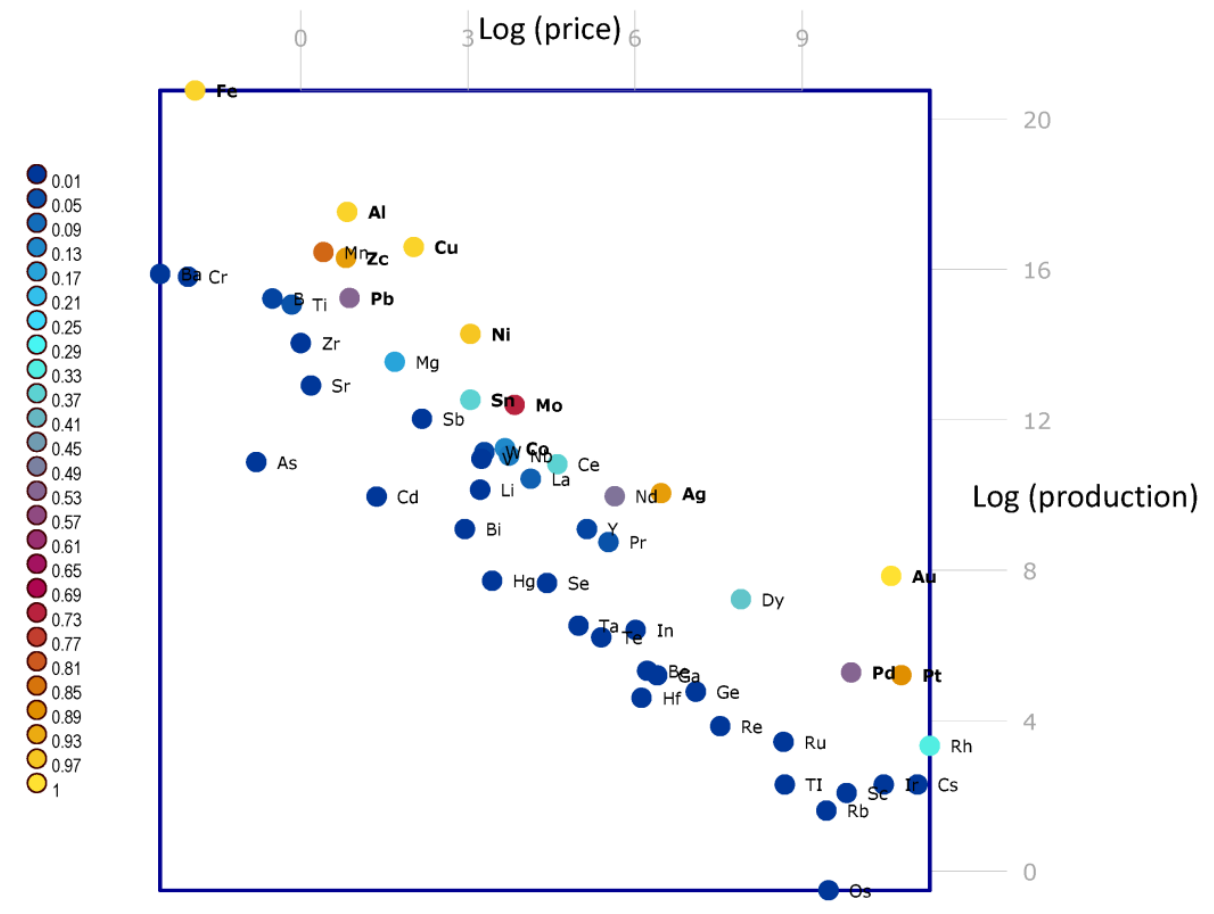

Figure 2 Price and Production of different metal markets associated with the probability to held futures contracts (computed with model B). Metals holding futures contracts are in bold. Source: author's calculations

For the other specifications, it seems that only price and level of production (cf. market size) are positively and significantly correlated with the presence of futures contract. The signs of the coefficients are indicated by theory developed in literature, which suggests that the larger the cash market, the larger the risk and hedging needs. We further suggest that cash market size is positively correlated with exchange volume, open interest, number of actors in the commodity market, and atomicity of the markets. ${ }^{10}$ Moreover, volatility of production (as the result of rapidly evolving demand) is negatively and significantly associated with the creation of futures contract (Gray, 1966). Conversely, though the model indicates a positive sign for the volatility of price, the effect is not significant; therefore, it does not confirm the arguments advanced by Telser (1981) and Maliaris (2000). There are various explanations for this absence of effect. First, we used annual data to estimate price volatility, so it is possible that annual price volatility is a poor indicator of the day-to-day volatility experienced by suppliers and consumers of metals. Second, price volatility makes futures contracts interesting as a risk-management tool, but this volatility must be predictable (Telser and Higinbotham, 1977). When the end use of a metal (e.g., indium) is limited and its demand can quickly increase or decrease, the metal's price is highly uncertain. Uncertain market conditions discourage speculators from using futures contract and reduce their interest in them. Finally, we find a negative and weakly significant effect of the geographical concentration of producing countries on the likelihood of presence of futures contracts.

\footnotetext{
${ }^{10}$ The correlation between geographical concentration and cash market size is negative. We suspect that figures based on industrial concentration (instead of geographical concentration) could provide a clearer picture.
} 


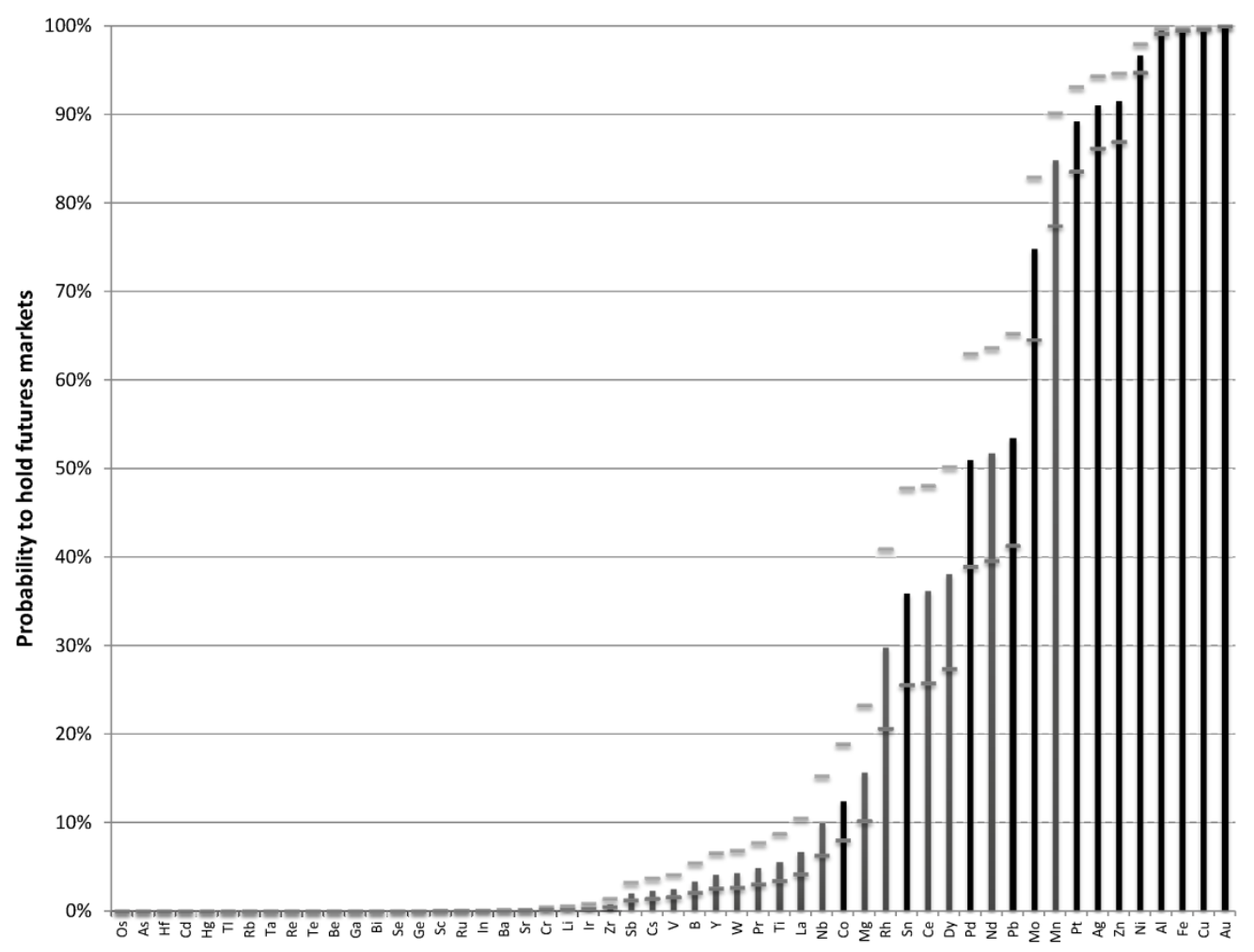

Figure 3 Probability to held futures contracts for each metal according to model $\mathrm{B}$. Confident interval are represented at $5 \%$ threshold risk while metal markets with futures contracts are in black. Source: author's calculations

\subsection{Model assessment}

The R-squared $\left(\mathrm{R}^{2}\right)$ value from McFadden and Nagelkerke estimations are quite high for all specifications. The probability that the various specifications of the model are not significant is very low (likelihood ratio [LR] statistic). The Hosmer-Lemeshow goodness-of-fit test also confirms the validity of the model. More precisely, at the 5\% threshold risk, we cannot reject the assumption of the goodness of fit of the model to data at an associated $p$-value of 0.99 . The indexes $g$ and gp represent the dispersion of the predictive value and the probability predicted. More conventionally, we use a confusion matrix (Tables 2 and 3) to assess the prediction quality of the model. In the case of Specification B, the prediction error is equal to $7.55 \%$, with $50 \%$ threshold success; that is, the model predicts futures contracts when the estimated probability is higher than $50 \%$. The prediction error can be computed as the expected mean of probability estimation error too, ${ }^{11}$ to avoid assumptions about thresholds of success. In this case, when the prediction error increases to $11.51 \%$, it is correct with a $88.49 \%$ rate. Moreover, the Brier score ${ }^{12}$ is good, at close to 0 (0.059).

\footnotetext{
${ }^{11}$ To obtain this value, we sum the estimation error of the model and divide by the number of observations: $\frac{1}{N} \sum_{i}^{n}\left(\widehat{p_{i}}-p_{i}\right)$.

${ }^{12}$ The Brier score equals $B S=\frac{1}{N} \sum_{i=1}^{N}\left(\widehat{p}_{i}-p_{i}\right)^{2}$. It fluctuates from 0 (model is never wrong) to 1 (model is always wrong).
} 
The prediction errors (Table 2 and 3) are the result of two separate errors: underestimation of the probability of presence of futures contracts (false negative, 2 cases) and overestimation of the probability to have futures contracts (false positive, 2 cases). Overestimations of the model may be explained by the existence of metal markets with highly controlled price and production (e.g., neodymium in China) or with a wide range of quality (e.g., manganese). Conversely, underestimation of the model may be the result of historical factors that our model does not take into account, such as the declining role of tin and increasing role of cobalt.

\begin{tabular}{|ll|c|c|c|}
\cline { 3 - 4 } \multicolumn{1}{c|}{} & \multicolumn{3}{c|}{ Estimated } & \multicolumn{1}{c|}{} \\
\cline { 3 - 4 } \multicolumn{1}{c|}{} & & FC=1 & FC=0 & Total \\
\hline \multirow{3}{*}{ Observed } & FC=1 & 11 & 2 & 13 \\
\cline { 3 - 4 } & FC=0 & 2 & 38 & 40 \\
\cline { 3 - 4 } & Total & 13 & 40 & 53 \\
\hline
\end{tabular}

Table 2 Confusion matrix. Prediction errors of model B with a success threshold at $\mathbf{5 0 \%}$. Source: author's calculations

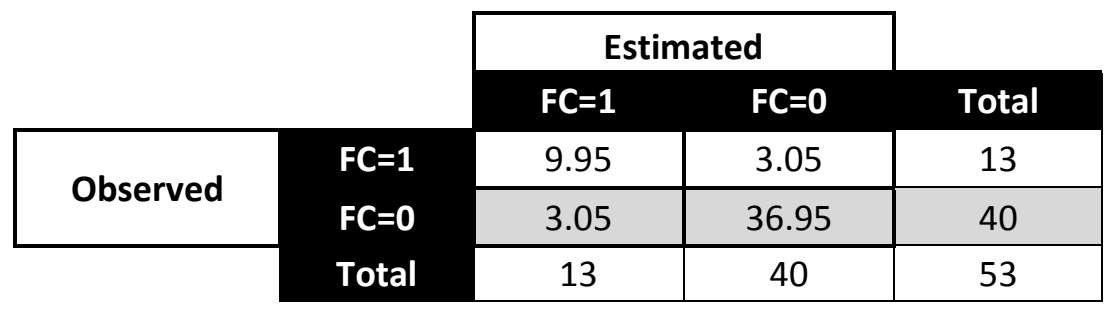

Table 3 Confusion matrix. Prediction errors of model B with expected value of probabilities. Source: author's calculations

The Mann-Whitney test is another indicator of the difference between the conditional distributions of positive and negative. It tests whether the model can correctly separate negative observations (i.e., without futures contract) from positive observations (i.e., with futures contract). In the case of Specification B, the Mann-Whitney statistic is equal to -5.08 with an associated $p$-value of $3.66 \times$ $10^{-7}$, so we reject the null assumption $\mathrm{H} 0$ of the test that the conditional distributions of positive and negative observations are similar, at $1 \%$ of the risk threshold (Figure 4). This result is supported by the receiver operating characteristic (ROC) curve, which depicts the relationship between the rate of true positives and the rate of false positives, depending on the score of the model (from 0\%-100\%). Ideally, a model that perfectly discriminates between positive and negative observations is characterized by a ROC curve in the northwest quadrant of the graph (Figure 5). Alternatively, a random model would produce an ROC curve close to the first bisector. The great advantage of this curve is its insensitivity to both the threshold success chosen and the unbalanced ratio between the number of positive and negative observations. A synthetic indicator of the ROC curve is the area under curve (AUC) criterion, which ranges between 1 (perfect discrimination) and 0.5 (no discrimination). In our case, all specifications of the model fluctuate between 0.97 and 0.9945 . 


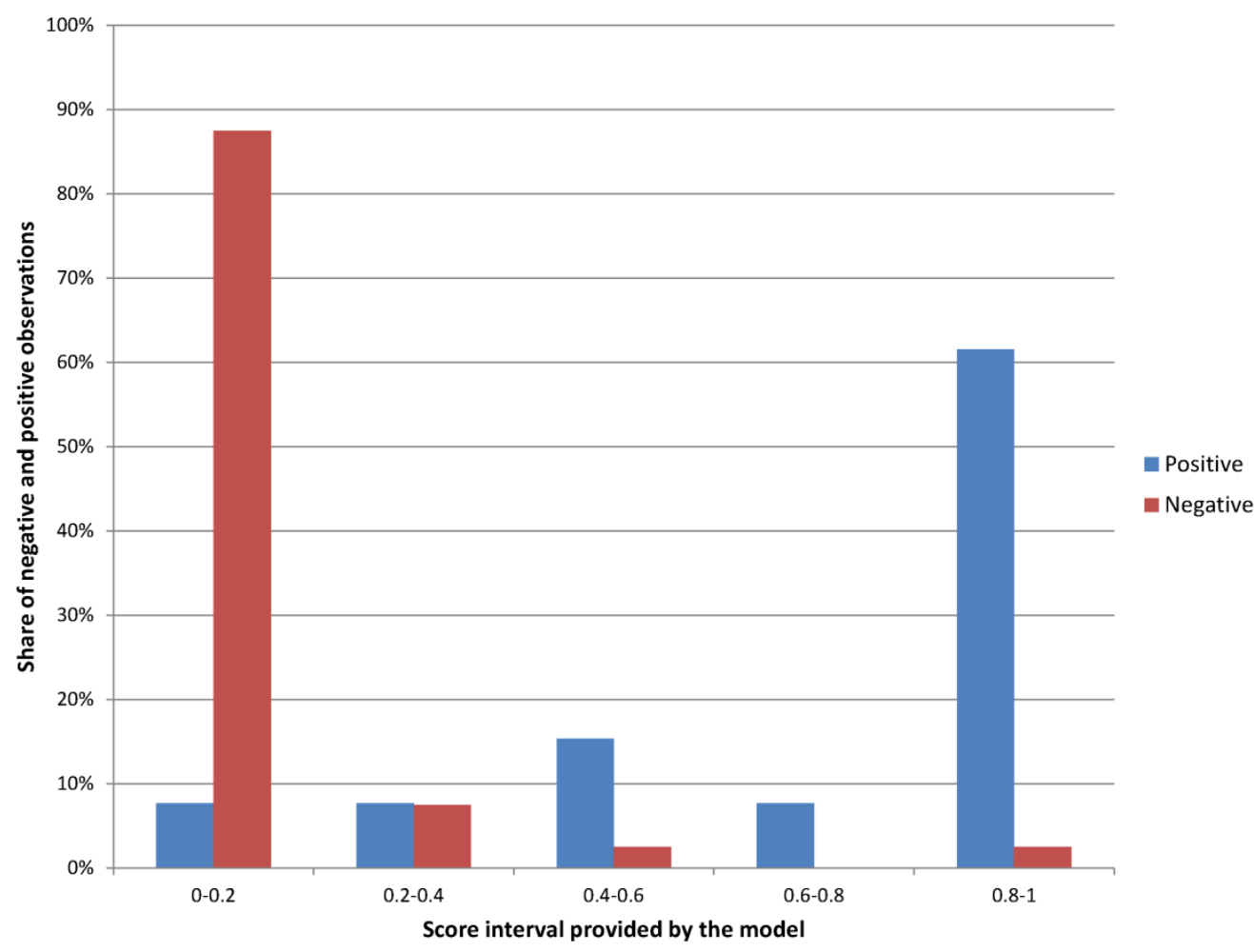

Figure 4 Conditional distribution of positive and negative observations with model B. Reading: the model separates very well positive observations (with high score) from negative observations (with low score).

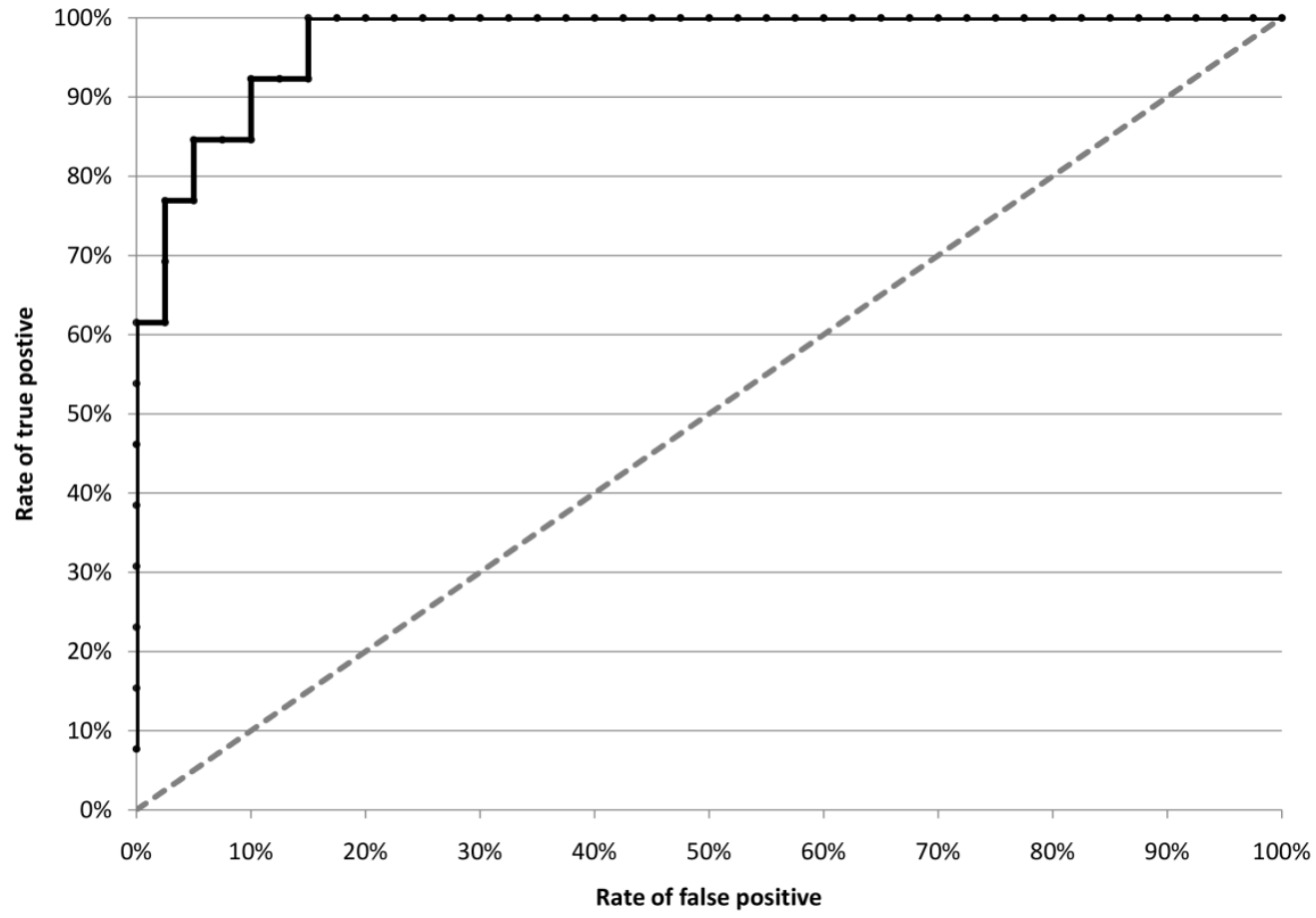

-ROC curve --.First bisector

Figure 5 Estimation of ROC curve from model B. 


\subsection{Robustness analysis}

Despite the goodness of fit of the various specifications of the model, we suspect that this result might not reflect the true predictive power of the model. We assess prediction errors using the same data that we used to calibrate the model, so there is the possibility of overfit, such that the model might fit the specificity related to the data of original sample but has limited ability to predict other data not used for the model calibration. To check for overfit, we use cross-validation and randomly generate training samples from the original data to calibrate the model. Then in a second step, we use this model to estimate the part of the data not used in the training sample and retrieve error estimations (and other fit criteria). Finally, we replicate these steps 20,000 times. Table 4 provides the results of this process.

We can obtain the AUC from the Somers Dxy criteria for the training and testing sample. ${ }^{13}$ With the resampling bootstrap process, we observe that the predictive capacity of the model is lightly overestimated because of the decline of the AUC, falling from 0.973 to 0.97 . Similarly, the Nagelkerke $\mathrm{R}^{2}$ falls from 0.7866 to 0.7596 and the Brier score from 0.059 to 0.0722 . Therefore, at the end of the process, the model exhibits little sensitivity to overfit, and its predictive power does not decrease very much, even in the case of random resampling. When we repeat this process with other model specifications, it produces similar results.

\begin{tabular}{|c|c|c|c|c|c|}
\hline Indicator & Original index & Training & $\begin{array}{l}\text { Testing } \\
\text { sample }\end{array}$ & Optimism & Corrected index \\
\hline Somers Dxy & 0.9462 & 0.9481 & 0.9418 & 0.0063 & 0.9399 \\
\hline R2 & 0.7866 & 0.7991 & 0.7721 & 0.027 & 0.7596 \\
\hline B & 0.059 & 0.0536 & 0.0668 & -0.0132 & 0.0722 \\
\hline $\mathrm{g}$ & 5.9369 & 7.7031 & 5.6154 & 2.0877 & 3.8492 \\
\hline gp & 0.3557 & 0.352 & 0.353 & -0.001 & 0.3567 \\
\hline
\end{tabular}

Table 4 Main results deriving from cross-validation based on 20000 bootstrap replications of model B. Source: author's calculations

\subsection{Out-of-sample predictions}

Out-of-sample predictions provide another way to check the estimation quality of the model; they can produce good predictions using a sample other than the original one used for calibration. Our model already relates to all metal markets, so we make predictions relative to the probability that other raw materials markets have futures contracts. Before applying Specification B (which requires little information), we must correctly identify the relevant geographical area for each commodity. Most metal markets are global, due to their low transportation costs and high values per volume/weight. Conversely, agricultural commodities are perishable and expensive to transport, which limits their trade to local or regional markets (i.e., they cannot realize spatial trade-offs at the global scale). They

\footnotetext{
${ }^{13}$ Somer Dxy $=2($ AUC -0.5$)$, which is equivalent to $A U C=\frac{D x y}{2}+0.5$.
} 
also are subject to seasonality, whereas metal products have uninterrupted production. We take this specificity into account to estimate the size of the cash market.

To cover a wide range of examples, we apply the model to natural resources without futures contract, natural resources with futures contracts, livestock, agricultural products, and energy resources (Table 5). The model shows mixed results. Although it accurately predicts the creation of futures contract (i.e., low false-negative rate), its ability to avoid false positives is limited. For example, according to Specification B, broiler markets (as studied by Hedge) should be large enough to promote the successful introduction of futures contracts. Yet history suggests the model might be missing important details, because futures contracts for this commodity have already failed three times. Conversely, the model accurately explains the unsuccessful introduction of futures contracts (i.e., their absence) for onions ( $\mathrm{prob}=0.40 \%$ ) and potatoes ( $\mathrm{prob}=6.6 \%$ ). Moreover, the model is relatively successful in assessing the presence of futures contracts for cereals, which likely is linked to the similarity of cereals and metals, relative to livestock; most cereals can be stocked for long periods (> 1 year) and have a degree of fungibility that is similar to that of metals. Although the model appears efficient for cereals, the very different characteristics of livestock and other agricultural products (e.g., fruits and vegetables) probably disqualify use its use for these categories of raw materials.

\begin{tabular}{|c|c|c|c|}
\hline Raw materials & $\$ / \mathbf{k g}$ & tons/year & $\begin{array}{l}\text { Probability to hold } \\
\text { futures contracts }\end{array}$ \\
\hline \multicolumn{4}{|l|}{ With futures contracts } \\
\hline Tender wheat (North America) & 0.209 & 83229000 & $70.01 \%$ \\
\hline Soybean (North America) & 0.415 & 94950760 & $94.53 \%$ \\
\hline Corn (North America) & 0.204 & 327879430 & $97.98 \%$ \\
\hline Oil (World) & 0.582735 & 3975000000 & $100.00 \%$ \\
\hline Uranium (World) & 130 & 53000 & $55.47 \%$ \\
\hline Orange juice (World) & 3.37 & 2564100 & $47.56 \%$ \\
\hline Cattle (World) & 4.025 & 63172915 & $99.95 \%$ \\
\hline Cattle (North America) & 4.025 & 13318056 & $98.31 \%$ \\
\hline \multicolumn{4}{|l|}{ Without futures contract } \\
\hline Champagne (grapes) & 7.158753 & 360845 & $6.57 \%$ \\
\hline Onions (USA) & 0.34 & 2900000 & $0.40 \%$ \\
\hline Potato (USA) & 0.203 & 18337537 & $6.66 \%$ \\
\hline Broiler (North America) & 1.489 & 18019205 & $90.66 \%$ \\
\hline
\end{tabular}

Table 5 Main results from out the sample estimation (with model B)

\section{Discussion}

Commodity prices and physical production (i.e., market size or value) are not the only factors contributing to the creation and success of futures contracts; however, our analyses show they are good approximations of the effects of other variables. We view the results of our model as preliminary 
(and necessary) conditions for the creation of futures contracts, rather than sufficient conditions. Our observation that the model has prediction errors is instructive, because it warns that most errors relate to metals with an intermediate cash market size (4-22 G\$, i.e Billions per year). In other words, the model correctly predicts the presence or absence of futures contracts for very big and very small cash commodity markets. It does not describe the mechanisms of this transition period or identify the trigger of futures contract creation when the cash market moves beyond this threshold size. It also does not explain changes in other variables that take place parallel to increasing market size values. However, the model reveals the crucial difference between the economics of major or precious metals versus those of minor metals. As cash commodity market size seems to play a fundamental role in the probability to hold futures contracts, one can ask what is leading small commodity markets to become large, diverse and transparent commodity markets. On this point, the study of Sykes et al. (2016) based on three historical cases ${ }^{14}$ show that "a transformational market growth" of small metals market required at least a combination of breakthrough in discovery, supply and demand. Indeed, scholars demonstrate that metal must meet discoveries in sufficient quantity (naturally abundant and geologically concentrated), overcome all challenges in the mining and processing of the metal and develop new and then broader end-uses to successfully achieve its transformation.

The limited number of observations $(n=53)$ requires taking these results with caution. We assess data for all metals markets, including the micro-markets of minor metals. We make this trade-off at the expense of the number of observations. These limits could be addressed in further work that uses panel data about major metals.

The model results indicate that some metals (mostly minor ones) are unlikely to create futures contracts in the near future, because of their small market size. Attaining the required threshold for many of these commodity markets would involve remarkable increases in production. For example, some financial institutions have raised the possibility of introducing futures contracts for lithium, notable for its key role in Internet Technology and Communication and its great ability to store electricity. Both Maxwell (2015) and the London Metal Exchange (LME, 2017; CNPC, 2017) have proposed the creation of futures lithium contracts. In 2010, the price of lithium, according to the United States Geological Survey and Metal-Pages, was nearly $\$ 25 / \mathrm{kgLi}$, and its production volume reached 25,350 tons per year. According to our model, the success probability associated with these figures is $0.3895 \%(0.3891-0.3899 \%)$. Therefore, it seems unlikely that there will be a successful introduction of a lithium futures contract in the coming years. At current price and production levels (and lithium is a fast growing market), this probability might increase to $2.39 \%[\$ 39 / \mathrm{kgLi} ; 35,000$ tons]. At a similar price, switching from the previous probability level to a $50 \%$ probability to have a

\footnotetext{
${ }^{14}$ Aluminum and nickel are analyzed as achieving successful case of transformation to large markets while uranium is used as a resounded failure case.
} 
futures contract would require additional lithium production of 180,000 tons - a fivefold increase in production (equivalent to a market size increase from 1.36 to $7 \mathrm{G} \$$ ). This increase is far more than that anticipated by Maxwell (2015: twofold increase) or Morgan Stanley report (Sanderson, 2018: 2.58 fold increase) by 2025 . Therefore, the recent announcement by the LME that it will introduce a lithium futures contract seems premature. It likely is based on a logic of competition with other exchanges (e.g., Shanghai Metal Exchange), rather than the criteria of success for futures metal contracts. When the cobalt and molybdenum markets were introduced in 2010, their market sizes were $4 \mathrm{G} \$$ and 11.2 G\$ respectively. Despite having larger markets than today's lithium market, they still struggled with liquidity concerns and low exchange volumes (Fizaine, 2015b; Reuters, 2016, 2016b). Historical evidence of the introduction of nickel and aluminum on the LME (in 1979 and 1978, respectively) shows that their cash markets were much larger than of lithium's current market (12 G\$ and $68 \mathrm{G} \$$ in constant dollars 2010). Our model indicates a high probability of creating futures contracts at these cash- market sizes (73\% for nickel and $98 \%$ for aluminum).

Anyway, this issue is not only theoretical but also involves practical concerns for producers and consumers of minor metals. Indeed, although price volatility in minor metal markets is higher than other metal markets (Fizaine, 2015b), it seems that there is no real open alternative to futures contracts in order to hedge this risk. Indeed, some scholars argue that there are other ways to hedge price risk taking, including vertical integration and cross-hedging although most of the time these practices are unsuitable or purely theoretical in case of minor metals. ${ }^{15}$

In turn, this study makes several contributions. First, rather than taking a monographic approach, we analyze all metal markets and provide information about factors that are likely to affect the introduction of futures contracts —or at least reflect the impact of other variables on the probability that a commodity has a futures contract. Second, our model is able to provide indications of the success or failure of futures contracts before their introduction; previous studies of this issue required the actual introduction of the market to deliver an opinion (via factors that affect open interest and exchange volume). The simplicity of our model (and the availability of data) makes it easy to apply to micro-markets, in which opacity is common. Thus the model should be useful to both public policy makers and private institutions that are interested in the survival of commodity futures contracts. It helps decision makers by revealing the preliminary conditions for the creation of futures contracts. Fulfillment of these conditions also allows analyses of other factors (mainly qualitative) that might affect the success and survival of futures contracts (i.e., characteristics of futures contracts and commodities). Third, our model expands on other studies that have focused on preliminary conditions

\footnotetext{
${ }^{15}$ This last method requires (1) sufficient information about historical cash market price evolution and (2) identifying futures markets (or combinations) that fit the evolution of the commodity price without futures markets.
} 
relative to industrial trading practices and commodity-market structures (Thompson et al. 1996) and provides a more complete explanation. Fourth, the variables and output of our model can be used as inputs for other empirical studies, conducted at the level of market structuring. For example, researchers could study the dynamic relationship between this study's variables and other parameters, such as quality, number of market actors, and degree of vertical integration.

\section{Conclusion}

We explore factors that affect the presence or absence of futures contracts for 53 metal markets. We offer a simple model that explains the probability of creating a futures contracts according to production of a commodity and its price per kilogram. We also detail other specifications involving production volatility that are useful. We demonstrate the model's predictive power, even in cases of random resampling. The model indicates the implausibility of futures contract creation (and survival) in the near future for almost all minor metals. However, generalizing this model to other natural resources is difficult, given the geographical delimitations of cash market influence. Nonetheless, its simplicity and ability to predict ex ante the probability of a commodity creating a futures contract makes the model useful to public policy makers and financial institutions. Although it does not provide definitive answers, the model offers preliminary answers to questions about futures contract creation for specific metals, while recognizing the need to study other qualitative factors that determine the survival and success of futures contracts.

\section{Acknowledgments}

I would like to thank J-E Carlotti and S. Ganneval for their helpful suggestions and comments about agricultural commodities. This manuscript was also greatly improved through all comments provided during the 7th International Research Meeting in Business and Management. I also thank anonymous reviewers and editor for their valuable comments. 


\section{Bibliography}

Arik, E., Mutlu, E., 2014. Chinese steel market in the post-futures period, Resources Policy, 42, 10-17.

Bicchetti, D., Maystre, N., 2013. Financiarisation des marchés de matières premières et conséquences, Economie Rurale, 337, 103-111.

Black, D. C., 1986. Success and Failure of Futures Contracts Theory and Empirical Evidence, Technical Report, Solomon Brothers Center for the Study of Financial Institutions.

Brooks, D. B., 1965. Supply and competition in minors metals, Johns Hopkins Press for Resources For Future, Baltimore, 150p.

Brorsen, B. W.,Fofana, N. F., 2001. Success and Failure of Agricultural Futures Contracts, Journal of Agribusiness, 19 (2), 129-145.

Brown, C. A., 2001. The Successful Redenomination of a Futures Contract: The Case of the Australian All Ordinaries Share Price Index Futures Contract," Pacific-Basin Finance Journal, 9, 4764.

Carlton, D. W., 1984. Futures Markets: Their Purpose, Their History, Their Growth, Their Successes and Failures, The Journal of Futures Markets, 4 (3), 237-271.

CNPC, 2017. 'Speculative frenzy' over electric cars and battery tech as investors mull lithium futures, accessed on 12/18/2017: https://www.cnbc.com/2017/10/04/investors-bullish-on-electric-car-batterytech-mull-lithium-futures.html

Daviron, B., 2012. Prix internationaux des produits alimentaires : volatilité ou hausse durable ?, Revue Tiers Monde, 3 (211), 91-109.

FAO, IFAD, IFAD, IMF, OECD, UNCTAD, WFP, World Bank, WTO, IFPRI, UN HLTF, 2011, Price Volatility in Food and Agricultural Markets: Policy Responses, Rome, FAO, 68 p.

Fizaine, F., 2013. Byproduct production of minor metals: threat or opportunity for the development of clean technologies? The PV sector as an illustration, Resources Policy, 38, 373-383

Fizaine, F., 2015a. Les métaux rares. Opportunité ou menace ? Enjeux et perspectives associés à la transition énergétique., F. Fizaine, Edition Technip, Collection Géopolitique, septembre 2015, 192p.

Fizaine, F., 2015b. Minor metals and organized markets: news highlights about consequences of establishing a future market into a thin market with a double trading price system, Resources Policy, Volume 46 (2), 59-70.

Goss, B. A., 1986. Feasibility and the consequences of using information in futures markets, in: Futures Markets: Their Establishment and Performance, New York University Press, pp. 1-12.

Gray, R. W., 1960. The characteristic Bias in Some Thin Futures Markets, Food Research Institute Studies, Volume 1, 296-313.

Gray, R. W., 1961. The Relationship Among Three Futures Markets, Stanford University, Food Research Institute Studies, Volume 2, 21-32.

Gray, R. W., 1966. Why Does Futures Trading Succeed or Fail: An analysis of Selected Commodities, Futures Trading Seminar, vol. III, MIMIR, Madison.

Gray, R. W., 1977. Price Effects of a lack of Speculation, in: A.E. Peck, ed., Readings in Futures Markets, Volume 2, Chicago: Chicago Board of Trade. 
Haase, M., Zimmermann, Y. S., Zimmermann, H., 2016. The impact of speculation on commodity futures markets - A review of the findings of 100 empirical studies, Journal of Commodity Markets, 3, $1-15$.

Hache, E., Lantz, F., 2013. Speculative trading and oil price dynamic: A study of the WTI market, Energy Economics, 36, 334-340.

Hedge, S. A., 2004. An Economic History of the Failure of Broiler Futures, Paper prepared for presentation at the American Agricultural Economics Association Annual Meeting (2004), 39p.

HLPE, 2011, Price Volatility and Food Security. A Report by the High Level Panel of Experts on Food Security and Nutrition of the Committee on World Food Security, Rome.

Houthakker, H. S., 1959. The Scope and Limits of Futures Trading, in: M. Abramovitz et al., The Allocation of Economic Resources, Stanford, California, Stanford University Press.

Humphrey, D., 2010. The great metals boom: a retrospective. Resources Policy, 35, 1-13.

Jacks, D. S., 2007. Populists versus theorists: Futures markets and the volatility of prices, Exploration in Economic History, 44, 342-362.

Kohls, R. L., 1955. Marketing of Agricultural Products, New-York, The Macmillan Compagny.

Leuthold, R. M., Jukus, J. C., Cordier, J.E., 1989. The Theory and Practice of Futures Markets, Lexington, MA: Lexington Books.

LME, 2017. LME announces strategic pathway delivery programme, accessed on 12/18/2017: https://www.lme.com/News/Press-room/Press-releases/Press-releases/2017/10/LME-announcesstrategic-pathway-delivery-programme.

Malliaris, A.G., 2000. Futures Markets: Why are they different?, in: A.G. Malliaris, ed., Foundations of Futures Markets: Selected Essays of A.G. Malliaris, 2000, chapter 1, pp. 8-25.

Maxwell, P.,2015. Transparent and opaque pricing: The interesting case of lithium, Resources Policy, 45,92-97.

Mayer, H., Rathgeber, A., Wanner, M., 2017. Financialization of metal markets: Does futures trading influence spot prices and volatility?, Resources Policy,53, 300-316.

Miffre, J., Brooks, C., 2013. Do Long-Short Speculators Destabilize Commodity Futures Markets?, International Review of Financial Analysis, 30, 230-240.

Mongars, P., Marchal-Dombrat, C., 2006. Les matières premières : une classe d'actifs à part entière ?, Banque de France, Revue de la stabilité financière, 9, 33-40.

N'Zue, F. F., 1995. Success and failure of agricultural futures contracts, how to best predict semivariance, and GARCH option pricing with implied volatility. Unpublished Ph.D. dissertation, Department of Agricultural Economics, Oklahoma State University, Stillwater.

Powers, M. J, 1967. Effects of Contract Provisions on the Success of a Futures Contract, American Journal of Agricultural Economics, 49 (4), 833-843.

Pirrong, C. S., Haddock, D., Kormendi, R., 1991. Grain Futures Contracts: An Economic Appraisal, Mid America Institute for Public Policy Research.

Redlinger, M., Eggert, R., 2016. Volatility of by-product metal and mineral prices, Resources Policy, 47, 69-77. 
Reuters, 2016a. Faced with falling volumes, what price liquidity for the LME?, accessed on 18/12/2017: https://www.reuters.com/article/us-lme-volume-ahome-column/column-faced-withfalling-volumes-what-price-liquidity-for-the-lme-idUSKCNOY911E.

Reuters, 2016b. LMEWEEK-LME may make molybdenum a cash contract, scrap steel billet futures, accessed on 18/12/2017: https://www.reuters.com/article/metals-lmeweek-contracts/lmeweek-lmemay-make-molybdenum-a-cash-contract-scrap-steel-billet-futures-idUSL8N1CR4OT.

Sanders, D. R., Manfredo, M. R., 2002. The White Shrimp Futures Market: Lessons in contract Design and Marketing, Agribusiness, 18 (4), 505-522.

Sanderson, H., Lithium prices to fall $45 \%$ by 2021, Morgan Stanley says, Financial times, 2018, available at: https://www.ft.com/content/66012fe2-1ae1-11e8-aaca-4574d7dabfb6 (accessed 8/07/2018).

Sykes, J. P., Wright, J. P., Trench, A., 2016. Discovery, supply and demand: From Metals of Antiquity to critical metals, Applied Earth Science, 125:1, 3-20.

Telser, L. G., 1981. Why There are Organized Futures Markets, The Journal of Law and Economics, $24,1-22$.

Telser, LG., Higinbotham, H.N., (1977). Organized Futures Markets: Costs and Benefits, Journal of Political Economy, 85 (5), 969-1000.

Thompson, S., Garcia, P., Wildman, L. D., 1996. The Demise of The High Fuctose Corn Syrup Futures Contract: A Case Study, The Journal of Futures Markets, Volume 16 (6), 697-724.

USGS, 2015. Mineral commodity Summaries 2015, accessed on 12/18/2017: http://minerals.usgs.gov/minerals/pubs/mcs/.

Veljanovsky, C. G., 1986. An Institutional Analysis of Futures Contracting, in: Futures Markets: Their Establishment and Performance, New York University Press, pp. 13-42.

Working, H., 1962. New Concepts Concerning Futures Markets and Prices, American Economic Review, Volume 52, 430-459.

World Bank, 2011. Global Economic Prospects 2009: Commodities at the crossroads, Washington DC. 